\title{
Animals - por uma nova zoolatria
}

\section{Carlos Alberto Orellana Gonçalves e Flora Ardenghi Dutra}

\section{Resumo}

0 artigo investiga a emergência de uma nova zoolatria, atrelada aos animais domésticos, especialmente apresentados em vídeos no Youtube. Através do vídeo Animals (Martin Garrix), a proposta de investigação analisa como a condição humana apresenta-se na forma de metáforas ligadas ao universo animal. Nossa metodologia contempla a análise da constituição do imaginário e dos universos míticos, por meio da mitocrítica de Gilbert Durand. Nossos achados evidenciam que esse movimento em direção ao registro por vídeo da vida animal é uma ação compensatória simbólica e também de uma reintegração do homem ao novo cenário no qual a natureza é revitalizada por discursos ecológicos.

\section{Palavras-Chave}

Zoolatria. Vídeo. Animais. Ambiente.

\section{Carlos Alberto Orellana Gonçalves}

Doutor em Comunicação pela Universidade Federal de Santa Maria - UFSM, Santa Maria, Rio Grande do Sul, Brasil. E-mail: lapisazul2984@gmail.com

\section{Flora Ardenghi Dutra}

Mestre em Comunicação pela UFSM, Santa Maria, Rio Grande do Sul, Brasil. E-mail: floradutra@hotmail.com

\section{Introdução}

Nosso artigo iniciou com uma investigação sobre os aspectos do imaginário em vídeos digitais, em particular, no Youtube. Acreditamos que os vídeos digitais constituem-se como um dos principais recursos de comunicação em redes digitais, e uma análise rigorosa dos seus aspectos míticos é imprescindível para compreender os fenômenos de comunicação contemporânea. Assumimos que as noções de imaginário são as bases da compreensão e da interpretação do mundo imagético ligado em rede. Desejamos entender de que modo o vídeo conjuga imagem técnica e imagem simbólica para a constituição de uma ambiência de lazer e de afetos como o Youtube, no qual os vídeos sobre animais constituem-se um dos exemplos.

Um dos formatos recorrentes de vídeos compartilhados em rede é do registro sobre animais, em geral, mimetizando os aspectos do humano ou do animal como fonte arquetípica. Portanto, analisar como esses vídeos são fontes de imagens simbólicas e de metáforas do humano 
pode revelar como a comunicação digital se constitui na contemporaneidade.

Compreendemos que, a partir dos anos 1960, nos países ocidentais, há um intenso debate político dos movimentos ambientalistas na pauta pública. Assumimos que os diversos problemas ambientais em escala global (aquecimento global, catástrofes, extinção, etc.), principalmente apresentados pelos meios de comunicação, conduziram a uma maior consciência social sobre as questões ambientais.

Ao lado desse intenso debate público sobre questões ambientais, como aponta Castells (2008), uma das estratégias básicas dos movimentos ambientais ao longo do final do século XX foi a atenção dos meios de comunicação para grandes eventos, 0 uso de ferramentas digitais e 0 aprofundamento do debate científico.

Essas estratégias alçaram as questões ambientais ao debate público, como foi o exemplo do Greenpeace, que usou sagazmente a penetração na comunidade acadêmica com emprego estratégico de ferramentas de comunicação para estar representada no debate público.

De acordo com Edgar Morin (2001), a Ecologia nasce como disciplina e, sob a forma de ecossistema, em uma ciência que, fundada no final do século XIX, conheceu um prodigioso desenvolvimento a partir do início dos anos de 1960. A noção de ecossistema significa que 0 conjunto das interações entre populações vivas no seio de uma determinada unidade geofísica constitui uma unidade complexa de caráter organizador: um ecossistema. Acompanhado de uma transformação radical nas taxas de natalidade dos países desenvolvidos, acreditamos que o decréscimo dessas taxas, ao final do século XX, permitiu uma maior atenção aos animais domésticos e uma encenação destes em redes digitais.

Desde o final dos anos 1960, em particular, nos países que compõem o 0cidente, há rupturas às formas tradicionais de sociabilidade, principalmente em relação ao patriarcalismo, às identidades sexuais e ao avanço dos movimentos sociais. De acordo com Castells (2008), nessa relação entre desaparecimento da família tradicional, planejamento familiar e ascensão do feminismo, há uma tendência geral ao decréscimo do tamanho das famílias nos países ocidentais. Levantamos a hipótese de que essa redução das famílias vem acompanhada do aumento da atenção aos animais domésticos e sua encenação em redes sociais digitais.

Além do debate público sobre as questões ambientais, a nova zoolatria vem embalada por uma atmosfera de lazer e de uma comunicação na qual as esferas privadas e públicas se interconectam. Portanto, a partir das transformações sociais ocorridas tanto no planejamento familiar quanto no crescimento da importância da ecologia no debate público, há um aumento dos registros em vídeo da vida cotidiana sobre os animais. 
Imagem simbólica: Gilbert Durand

A imagem simbólica, na obra de Durand (2002), é apresentada como o próprio substrato no qual as mais distintas sociedades relacionam-se. Ela configura-se como resultado da trajetória antropológica do homem no seu ambiente. A imagem, em Durand (2002), constitui-se a partir das bases de Bachelard e de Jung, isto é, ela encontra-se num tensionamento entre uma pretensão ao futuro de se materializar e servir à constituição de um projeto de identidade (perspectiva de Bachelard). A segunda perspectiva, a junguiana, é a de que as imagens simbólicas estão organizadas como num banco de dados. Durand (2002) associará essa ideia de que as imagens organizam-se por um eixo biofisiológico (perspectiva da etologia e da zoologia) do corpo humano e que estão acessíveis à espécie humana como um todo.

Desse modo, o grande avanço teórico epistemológico vai se constituir num campo de análise vasto e profundo sobre as condições pelas quais as imagens desenvolvem-se, como elas organizam-se e produzem novas imagens que, em seu conjunto, formam três eixos básicos de estruturas imaginárias: mítica heroica, mítica mística e mítica dramática. $\mathrm{Na}$ primeira, os gestos ascensionais de subida, elevação e colocar-se de pé produzem um afastamento e, ao mesmo tempo, a dominação da natureza pelo homem. Na mítica mística, os gestos correspondem às imagens de descida, escavação, interiorização. Nessa estrutura imaginária, o conflito se resolve por meio de imagens de fecundidade, prudência, lentidão e abundância. Esse gesto manifesta-se por reflexos de sucção labial e por dominante digestiva no ato de deglutição que age como princípio de organização, como uma estrutura sensório-motora. A terceira estrutura imaginária corresponde à harmonização das duas anteriores estruturas imaginárias, isto é, há um processo em que esses dois universos andam numa relação de coincidência e de equilíbrio.

Acima de tudo, a obra de Durand (2002) permite-se compreender de que modo a imagem simbólica também produz ação ao relacionar as noções de mito e rito, buscando tanto o mito em sua função de núcleo dramático do imaginário (DURAND, 2002) quanto o de formador de condutas, práticas e organizações (MAFFESOLI, 2006). Portanto, esses autores reconhecem como essas estruturas presentes fazem sentido aos grupos sociais.

A imagem, em Durand (2002), torna-se uma metáfora de banco de dados acessível à espécie humana, processo pelo qual apreendemos o campo simbólico, estrutura pela qual compreendemos a trajetória humana pelo planeta, o núcleo das estruturas do imaginário e, junto com 0 mito e 0 rito, é formadora de condutas, práticas e organizações.

Havíamos destacado a posição central da obra junguiana para a compreensão de imagem em Durand (2002), da acessibilidade ao arquivo de imagens da espécie humana que seria estruturante de nossa compreensão de mundo. 
Aqui destacaremos duas ideias centrais que guiam a noção de imagem em Durand (2002).

Ele enfatiza que, independentemente das condições materiais e culturais de cada sociedade, há um meio pelo qual todas desenvolvem uma relação de interdependência. Esse meio seria condição fundamental para 0 desenvolvimento do trajeto humano ao longo de sua história como espécie, já que ela existiu antes mesmo de uma estrutura linguística. 0 que destaca Durand (2002) é que as imagens e as estruturas imaginárias serão a primeira linguagem que 0 homem usa para mediar sua experiência com a natureza, mas que, ao mesmo tempo, cria as condições de produção de novas imagens num efeito ad infinitum. Mas, se temos uma linguagem primeira que desenvolve nossa mediação com o ambiente, como ela funciona e de que modo ela se organiza? As respostas a essas questões fundamentais vieram das investigações de Durand (2002) sobre a etologia e a zoologia moderna. Até mesmo a noção junguiana de arquétipo como sendo a matriz das grandes imagens é primordial a Durand (2002), em sua apropriação e desenvolvimento das condições de produção imagéticas das sociedades.

\section{Zoolatria: aspectos míticos}

De acordo com Durand (2002), o simbolismo ligado ao universo animal está presente em todas as culturas e é ensinado ainda na infância, isto é, constitui-se por sua universalidade e banalidade. Ainda segundo Durand (2002), o teriomorfismo (simbolismo com metáforas animais) constitui- se como uma das forças de imaginação mais profundas, e os animais desempenham um papel psicanalítico importante como figura metafórica da libido sexual.

Em nosso trabalho, vamos usar como sinônimos os termos simbolismo animal, teriomorfismo e bestiário como uma tentativa de compreender esse fenômeno tão antigo que mantém resíduos nas relações sociais mais diversas, em particular, nas relações de comunicação digital. Durand (2002) acredita que 0 bestiário está solidamente instalado não apenas na língua e nas narrativas, mas particularmente na mentalidade coletiva e nas fantasias individuais. Assim, acreditamos que uma investigação sobre bestiário, simbolismo animal ou teriomorfismo é condição básica para compreender as relações sociais contemporâneas e como elas revelam parte do desenvolvimento da comunicação em rede. Entretanto, o mesmo autor (2002) deixa claro que cada animal representa um conteúdo simbólico próprio e que a escolha de cada animal em mitos ou outras narrativas representa uma sobreposição de conteúdos semânticos. E é tarefa daquele que pretende investigar as condições simbólicas compreender essa sobreposição de semantismos ao longo de um dado período.

Portanto, cada animal aciona um determinado arquétipo que, de acordo com Durand (2002), liga-se a imagens muito diferenciadas pelas culturas e no qual uma série de esquemas vêm se imbricar. Desse modo, nossa análise mitocrítica vai investigar quais são os arquétipos acionados 
e como eles se imbricam dentro de uma cultura que promove 0 ambientalismo e em que se dedica cada vez mais recursos e tempo aos animais domésticos.

Compreendemos a nova zoolatria como um aspecto residual do imaginário social arquetípico e como elemento dinamizador da pauta ambiental, em particular, dos movimentos ambientalistas.

A imagem de Giuseppe Arcimboldo intitulada 0 Outono (1573) representa bem nosso atual imaginário contemporâneo ambiental, isto é, há um retorno dos aspectos mais profundos de nossa relação com a natureza e uma metaforização da natureza como palco de encenação do humano. 0 papel dos estudos ecológicos e a ascensão do debate da ecologia nas mídias e no plano político criaram uma atmosfera propícia para a atenção aos animais em vídeos digitais.

Acreditamos na pertinência da zoolatria num momento em que as fronteiras entre cultura e natureza tornam-se cada vez mais porosas.

Figura 1: 0 Outono, de Giuseppe Arcimboldo

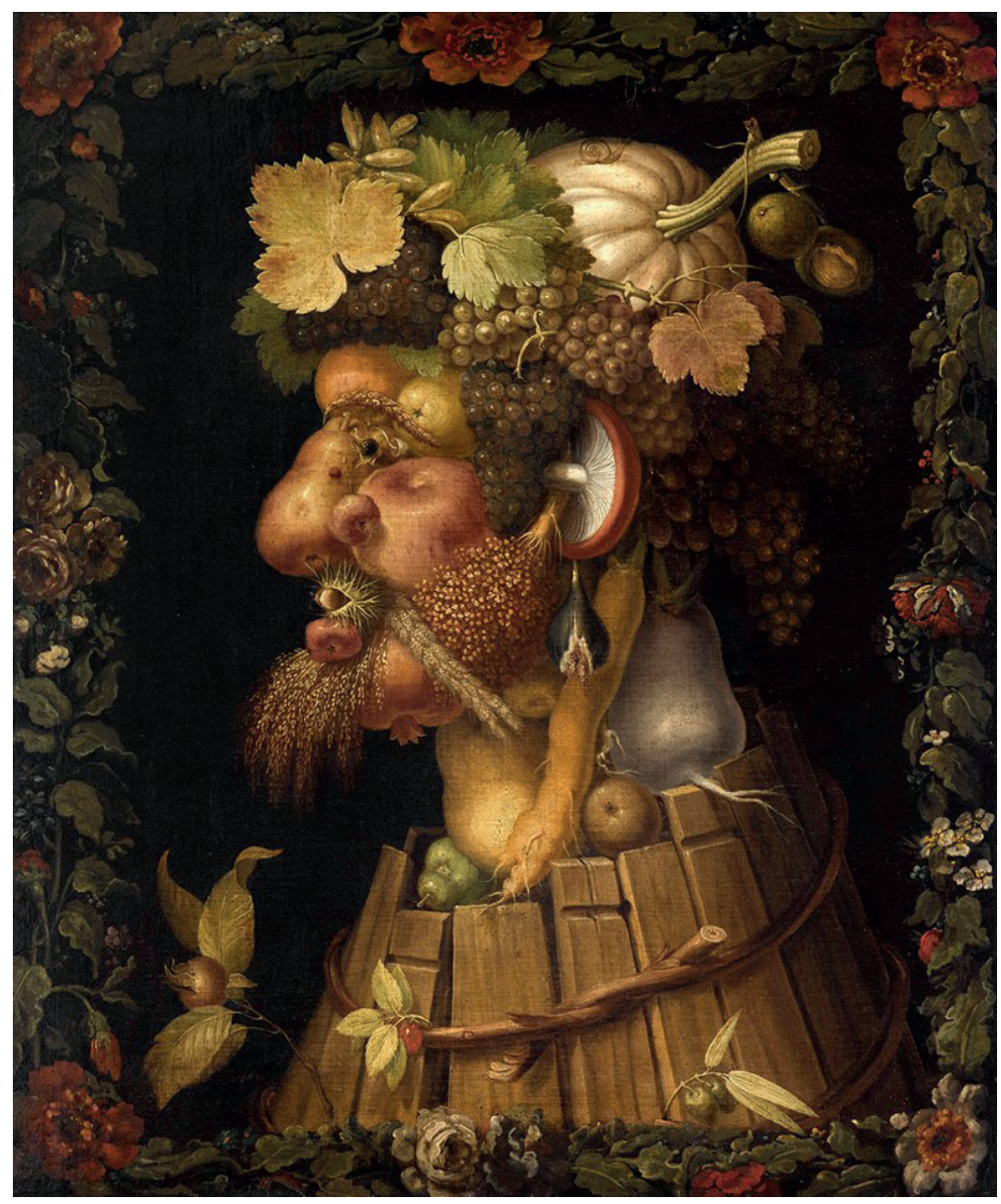

Fonte: Acervo digital do Museu do Louvre (2017). 
A lição dialética entre cultura e natureza será a base em que vai se constituir, na Antiguidade, e vai se aprofundar, na Idade Média, o pensamento racional ocidental, como analisa Flusser (2011). 0 pensamento aristotélico tornou-se a base da compreensão ocidental, pois ele fundou-se numa práxis artesanal, numa ideologia latifundiária e mercantil ateniense que será o motor de produção material no mundo medieval ao refletir um estar-no-mundo. Entretanto, a lógica dialética aristotélica continua entre natureza e cultura, como explica o autor:

[...] tudo que é necessário e dispensável chamo "natureza", tudo que é desnecessário e indispensável chamo "cultura". Progresso é transformar coisas necessárias e dispensáveis em desnecessárias e indispensáveis. Natureza é anterior à cultura, e progresso é transformar natureza em cultura (FLUSSER, 2011, p.80).

Há uma divisão entre essas duas visões de relação entre natureza e cultura. A primeira, metafísica (aristotélica/platônica), concebe essa relação em termos dicotômicos e de utilitarismo pragmático; a segunda, de linha fenomenológicoantropológica (DURAND, 2002; FLUSSER, 2011), compreende essa relação como jogo integrador do homem na própria esfera simbólica.

\section{Metodologia: a mitocrítica da zoolatria em rede}

Selecionamos um vídeo chamado Animals, de Martin Garrix, como metáfora dessa nova zoolatria e usamos exemplos coletados no
Facebook e Instagram para reforçar nossa pesquisa sobre a temática. Usamos o vídeo de Martin Garrix como um índice de um movimento maior que acontece em redes sociais e que batizamos de nova zoolatria. Privilegiamos uma metodologia de análise da constituição do imaginário e dos universos míticos (DURAND, 1994, 1996, 1999, 2002; BACHELARD, 1989, 1993, 1996, 1999, 2011). Priorizamos tal aporte metodológico por ir às profundezas da estrutura imaginária e, ao mesmo tempo, reconhecer as estruturas que repercutem sobre a paisagem dos fenômenos culturais contemporâneos.

Durand (1996) propõe uma mitocrítica que leve o imaginário como um saber entre saberes, isto é, um conjunto de saberes que estaria entre as disciplinas. 0 autor propõe que 0 estudo sobre o imaginário deve ser compreendido como um museu de imagens ou reserva de museu, ou seja, como um conjunto de imagens produzidas pelo homo sapiens até 0 atual estado temporal. Assim, Durand (1996) analisa que a imagem invade todos os campos do saber a partir do final do século XIX, como a química dos suportes e a física das comunicações. Neste sentido, como o autor enfatiza (1996), é o imaginário que emerge em todas as disciplinas e as reforça. A emergência dos estudos sobre imaginário surge, num primeiro momento, nas letras e artes, no sentido de compreender os sentidos históricos atribuídos às imagens no Ocidente, particularmente, nos períodos como Renascimento, Barroco, Romantismo, etc. 
Durand (1996) aponta Bachelard como um dos pioneiros neste estudo hermenêutico interdisciplinar das imagens. Assim, de acordo com Durand (1996), esses estudos literários e artísticos sobre os sentidos das imagens foram as bases por meio das quais se desenvolveu a mitocrítica praticada pela Escola de Grenoble. Desse modo, propomos, ao longo de nosso trabalho, um exercício hermenêutico interdisciplinar que leva em conta os aspectos da imagem em seu contexto simbólico como no aspecto social de produção de sentido. Contamos com os aspectos sociológicos como ferramentas para aprofundamento do sentido social das imagens técnicas, ou seja, contamos com o instrumental teórico de autores como Castells (2005), Jameson (2006), Maffesoli (2006) para elucidar as condições sociais de produção da imagem técnica. Partimos da premissa de trabalhos de Dumézil (1973) como fórmula para um estudo interdisciplinar dos aspectos simbólicos das imagens contemporâneas, ou seja, consideramos as condições sócio-históricas como elementos fundamentais para integração da imagem simbólica dentro de uma pesquisa em Comunicação.

Ainda de acordo com Durand (1996), foi a Etologia, ciência do comportamento animal, junto aos estudos do poder simbólico e suas diversas manifestações, que permitiu a emergência dos estudos do imaginário. Portanto, como avalia Durand (2002), há a necessidade dessa transdisciplinaridade na busca dos confins dos sentidos das imagens.
Segundo Durand (1996), o imaginário não se constitui como disciplina no sentido de um saber petrificado, mas como um lugar entre-saberes que vem revitalizar as condições de compreensão da imagem e de como esses sentidos imagéticos produzem uma compreensão do real. Assim, o autor (1996) aponta a necessidade da transdisciplinaridade das 'disciplinas' modernas para conseguir resgatar os símbolos como constitutivo do funcionamento específico do pensamento humano.

0 presente trabalho, dentro de uma perspectiva interdisciplinar dos estudos do imaginário e sociológico sobre o fenômeno do vídeo em redes digitais, justifica-se, como defende Durand (1996), por dois pontos. Um deles é a oportunidade histórica de compreender um fenômeno contemporâneo de comunicação que interliga diversos atores sociais: sujeitos, redes digitais de comunicação global, grupos sociais. 0 outro é o próprio vídeo visto como um agente não humano. Ainda, o fenômeno do vídeo em redes digitais invade as pautas de jornais, os programas de entretenimento e torna-se o motor de interações entre sujeitos dentro de redes digitais. Compreendemos que há uma grande oportunidade de verificarmos quais elementos são constitutivos dessa comunicação imagética.

\section{Animals e a mitocrítica de Durand}

0 vídeo analisado trata-se de Animals, de Martin Garrix, e sua noção de zoolatria. Acreditamos que, 
dentro dessa renovação da natureza no discurso social na contemporaneidade, surge também uma zoolatria disfarçada em uma atenção maior aos animais domésticos, no uso de animais como metáforas ao desenvolvimento humano e no animal como lugar de alteridade, o lugar do outro. Portanto, vamos elencar alguns mitos, como o de Zeus, que, muitas vezes, surge em sua forma zoomórfica para atender às suas necessidades ou, mesmo, como destaca Durand (2002), que a zoolatria é ensinada desde a mais tenra idade como método de compreensão das possibilidades humanas.

A imagem é também concebida não só como práxis, mas como uma espécie de guia de sentidos e significados, e é a partir deles que são produzidos modos de fazer, de agir e de viver as mais diversas situações do campo social. Trata-se de um conjunto de regras mais ou menos reconhecidas e vivenciadas que extrapolam a própria condição da imagem simbólica, mas desejando sempre se fixar em uma materialidade que, por sua vez, produz as condições de produção da imagem técnica devedora e, ao mesmo tempo, redundante dessa imagem simbólica.

No vídeo Animals, de Martin Garrix, podemos encontrar um tom celebratório e de emancipação dos animais-sujeitos que se encontram numa

Figura 2: Videoclipe Animals, de Martin Garrix

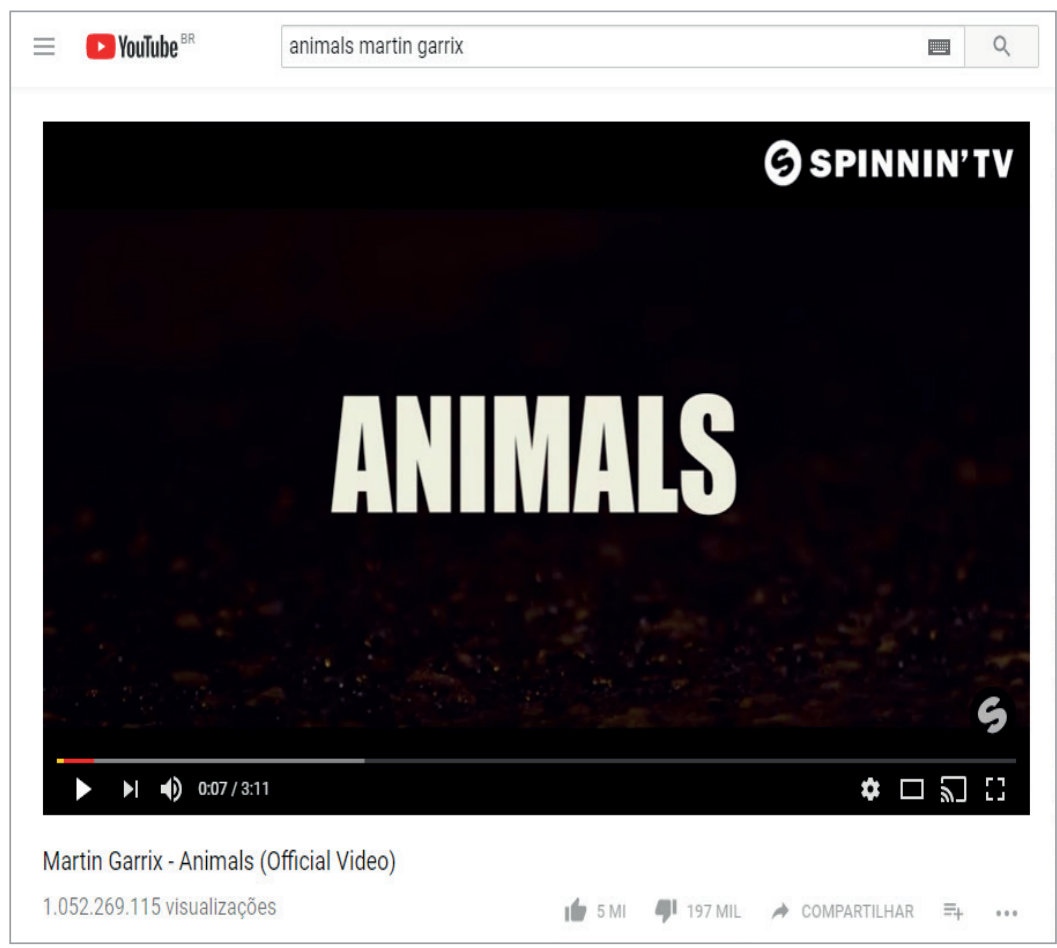




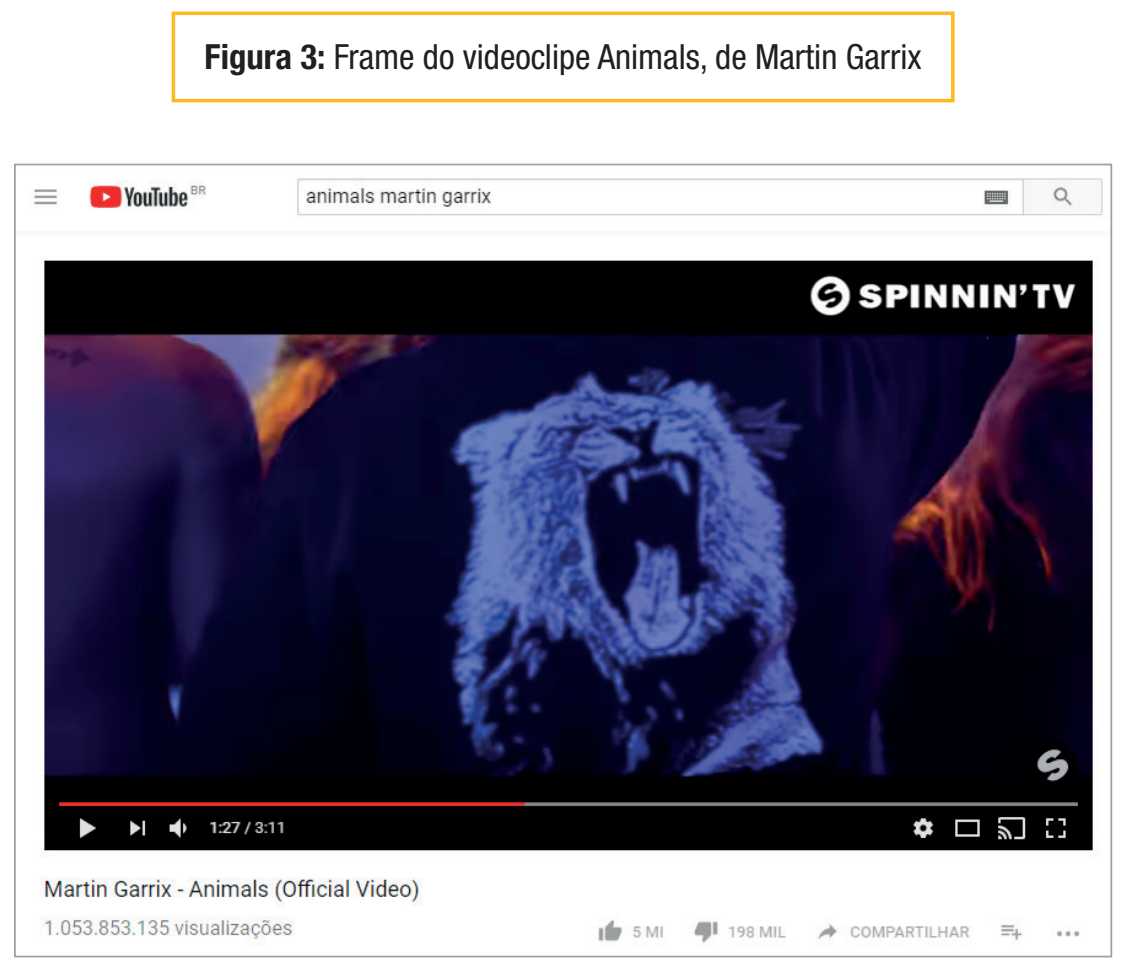

Fonte: YouTube (2016).

cena em que jogam dados e cartas, apostam e vão dançar como numa boate. Há um grupo de pessoas com máscaras de animais (coelho, tigre, urso, rato) que chegam ou 'invadem' o espaço dos seres humanos, e o videoclipe acentua as imagens dos gritos ou sons guturais, que são representados pelas imagens de animais tanto nas costas das blusas desse grupo como na imagem em si.

Compreendemos que o videoclipe Animals representa uma metáfora do novo estatuto dos animais em nossa sociedade que transita entre um tom celebratório, de atuação dos movimentos ambientais e de zoolatria. Os animais assumem o papel de destaque e, consequentemente, da natureza do debate político e social.
No simbolismo do animal selvagem, em particular, Durand (2002) aponta o vetor dos movimentos bruscos como um valor negativo associado ao mal, como, por exemplo, os cavalos, os touros, as águias e diversos mitos que associam os animais selvagens ao mal, ao desastre, à ação violenta. Para o autor, há um bestiário que concentra sobre os animais selvagens todos os fantasmas da animalidade: agitação, mastigação agressiva, grunhidos e rugidos sinistros. E acreditamos que há uma ação simbólica compensatória nos animais domésticos.

De acordo com Durand (2002), o grito animal representa o esquema de voracidade sádica, no qual a boca é simbolicamente interpretada como fonte do desastre e de atenção contra 0 mal. 
Assim, a deglutição constitui-se como a grande epifania da animalidade. Esse traço da boca ou do grito animal pode se constituir como um símbolo no qual os gritos servem para encenar suas vidas em vídeos digitais. Acreditamos que a encenação do grito como fantasia do medo e das apreensões arquetípicas contra o mundo animal assume um papel de dar voz àqueles que ainda não têm. 0 grito funciona como metáfora da nova encenação e do novo lugar do animal e da ecologia no mundo contemporâneo. Os medos e os fantasmas arquetípicos que povoavam a presença dos animais vêm dar lugar ao mundo do animal como o outro ou como metáfora do humano.

De acordo com Durand (2002), o medo da morte devoradora é ricamente representado pela iconografia europeia, em particular a medieval, em que esses temas teriomórficos vivem nos mais diversos contos. Entretanto, o lugar do medo dá espaço para o risível, ou seja, do afeto e do lazer em vídeos digitais. 0 terror e a insegurança dão lugar ao gracejo, à euforia, à celebração. Acreditamos que essa mudança do lugar do animal é resultado da encenação do outro ou da alteridade em redes digitais.

Além disso, como observa Durand (2002), 0 homem tem uma tendência para animalização de seu pensamento e são recorrentes os rituais nos quais humanos desempenham o papel de animal. Como no vídeo acima, em que pessoas mascaradas simulam o papel de animais e recriam uma sociabilidade celebratória e festiva, essa assimilação do universo animal pelo homem em parte pode ser explicada pela teoria psicanalítica, como aponta Durand (2002), na qual cada animal representa uma parte do espectro dos sentimentos humanos e símbolo da libido sexual.

De acordo com Durand (2002), o símbolo é anterior tanto cronológica quanto ontologicamente sobre qualquer significância audiovisual, isto é, o símbolo é a base constitutiva para qualquer ação do homem sobre o campo cultural. Como o vídeoclipe é apresentado numa boate, essa relação entre a metáfora animal e a libido torna-se um importante ponto de investigação ou como uma evidência de que a nova zoolatria nasce também dentro de um contexto de pluralização de sexualidades e de gênero. Sugere uma possibilidade de estar aberto a novas condições identitárias, no qual a libido não é elemento restritivo ou de punição (como durante a Modernidade), mas um elemento a ser celebrado e festejado numa espécie de conquista de si.

Um dos elementos visuais que servem para entender essa nova relação que mantemos com as questões ambientais é o relógio em estilo tradicional que o personagem do videoclipe carrega, uma metáfora de que as antigas temporalidades já não fazem mais sentido na lógica contemporânea, pois o relógio-tempo se desfaz em relação à aceleração dos discursos.

Acreditamos que essa lógica de diversas temporalidades invadindo o espaço cênico do videoclipe seja uma noção do passado que se 
Figura 4: Relógio tempo antigo versus condições temporais contemporâneas

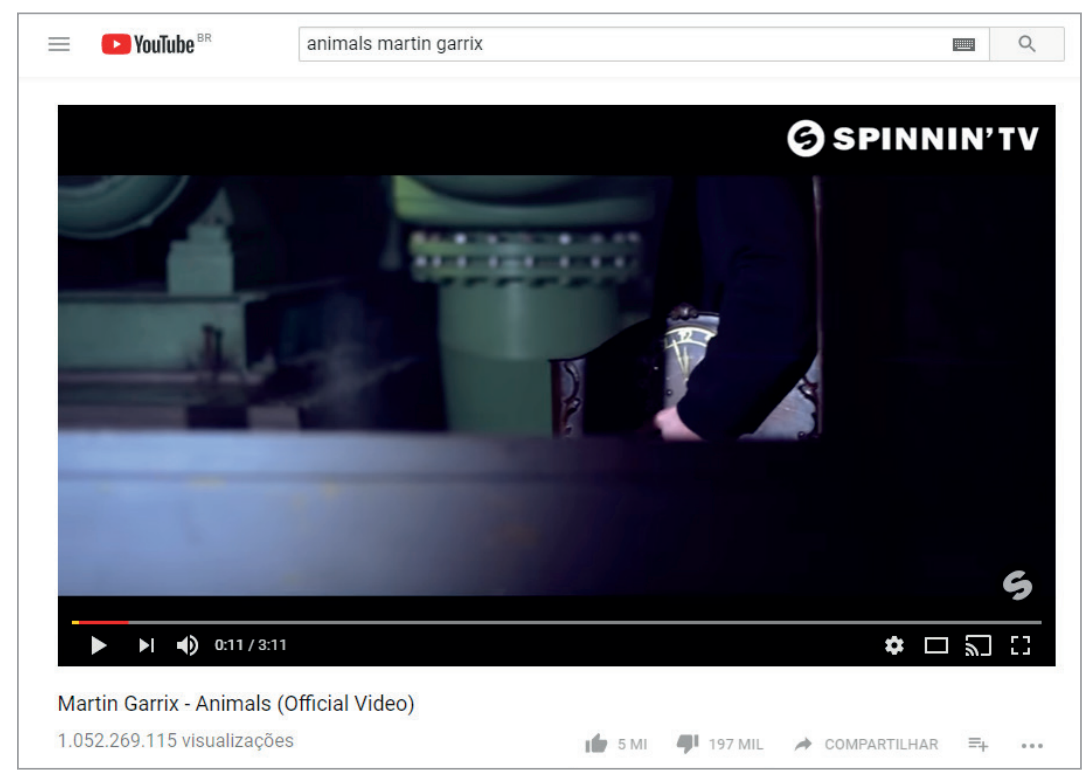

Fonte: YouTube (2016).

acumula, como descrito por Deleuze (2004), em relação a como vivemos o tempo. A temporalidade dos animais e a do humano são sincronizadas, sugerindo uma conciliação do tempo ecológico com o tempo social humano, encenado num espaço de celebração, a boate.

Assim, a carga de imagens que se refere a múltiplas temporalidades vem dar coerência ao presente que se esvazia e que necessita de uma solidez em sua liquidez. Devemos compreender que a memória, no sentido de Bergson (2011), isto é, ter consciência sobre o passado, é o principal recurso para compreensão do nosso lugar no mundo.

No plano simbólico, "a existência no Tempo é ontologicamente uma inexistência, uma irrealidade [...]. 0 mundo histórico, as civilizações duramente construídas pelo esforço de milhares de gerações não existem no plano dos ritmos cósmicos" (ELIADE, 2002, p. 64). Neste sentido, compreendemos que esse resgate arqueológico contemporâneo serve como elemento de equilíbrio para reintegrar nosso tempo de aceleração do presente ao ritmo do Tempo, dos ciclos maiores e revelar a precariedade da produção técnica e a necessidade de compreender os ritmos da vida, da natureza.

Essas temporalidades também podem ser compreendidas pela lógica da instauração de uma temporalidade em que a velocidade torna-se parâmetro para todas as atividades humanas. Como Virilio (2015) aponta, numa lógica de aceleração e racionalização dos ritmos de vida, 0 videoclipe surge como modelo exaustivamente 
copiado: os dois ou três minutos como fórmulas de atenção e produção estética contemporânea. Essa aceleração foi combinada pelo avanço de múltiplas telas e da Internet banda larga em dispositivos móveis. A necessidade de encurtar o tempo das narrativas para se ajustar a uma atenção fragmentada do usuário, fragmentação da audiência clássica (dos meios tradicionais de comunicação) versus uma audiência em ascensão (youtubers, celebridades etc.), sobreposição da mesma narrativa em múltiplos canais de divulgação (livros, filmes, páginas em rede sociais, canal no YouTube), etc.

Portanto, essa metáfora de sincronização temporal (ecológico e humano) é um traço de um retorno da zoolatria, isto é, uma metaforização dos aspectos humanos através das imagens do bestiário. As imagens de animais em nosso imaginário, de acordo com Durand (2002), corresponderiam às necessidades de liberação de aspectos da libido, e cada animal exerce uma função simbólica para compreender cada faceta da relação humana com o real. Assim, verificamos que, nos vídeos em redes digitais, como YouTube, há um movimento ascendente de registro das eventualidades da vida dos animais domésticos sendo traduzidos em termos de metáforas das ações humanas, o que cria 0 efeito de correspondência.

A Ecologia como ciência ganha o espaço de discussão social a partir da década de 1960, dentro de um contexto de uma economia pós-industrial e do impacto da industrialização

e do arsenal atômico sobre 0 ambiente no planeta, buscando uma compreensão mais holística sobre as condições de sobrevivência das espécies como uma grande teia na qual há uma interdependência entre os diversos seres. Os animais aqui pesquisados nos vídeos não são apenas pensados como metáforas do humano, mas também como atores não humanos, isto é, como uma consciência que decompõe a hierarquia vertical e compõe uma maior simetria entre humanos e não humanos.

Além disso, apontamos que a zoolatria em vídeos em redes digitais compreende, particularmente, os animais domésticos, numa inserção desses animais como atores de um novo cenário global no qual há a redução da natalidade em países desenvolvidos, sendo os animais domésticos 0 centro da atenção em muitos lares. Num vídeo realizado pelo próprio YouTube, intitulado 'The A-Z of YouTube: celebrating 10 years', a primeira seção é dedicada aos vídeos famosos de animais. Nesse vídeo comemorativo, são apresentados alguns animais que foram célebres dentro da rede de vídeos como o gato malhumorado que recebeu diversos memes em redes sociais, como Facebook, Twitter e YouTube.

0 YouTube consagra um vídeo sobre os temas de vídeos mais vistos na rede. E o tema dos animais desperta a atenção, acreditamos, devido a esse depósito de formações simbólicas que se relacionam ao universo animal e que repercutem 
Figura 5: Vídeo comemorativo do YouTube em que celebra os vídeos sobre animais.

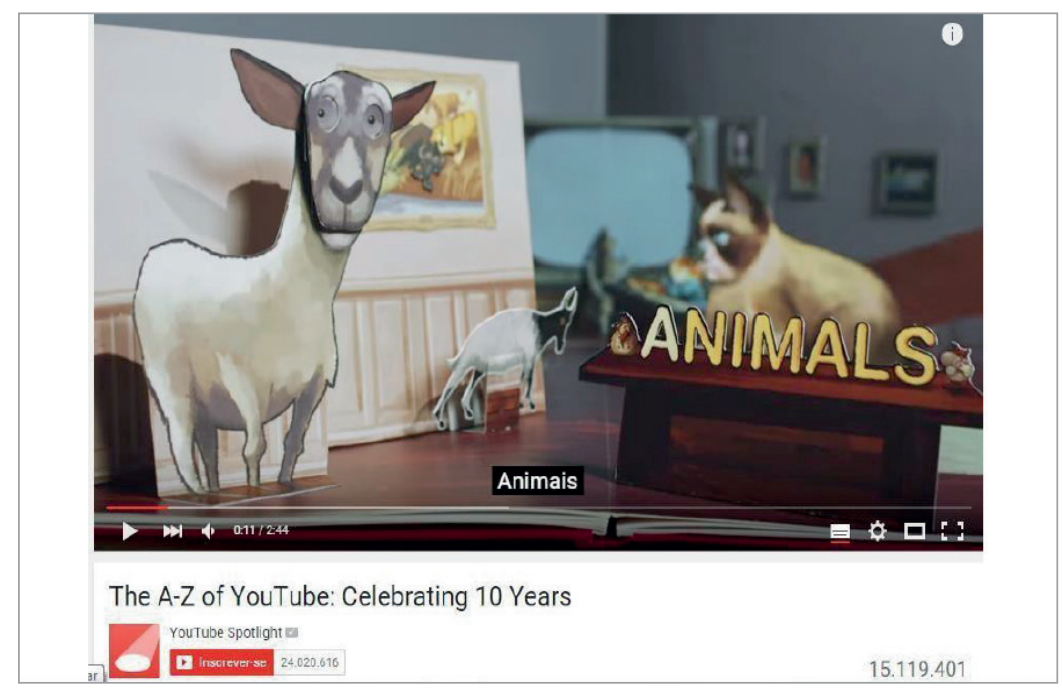

Fonte: YouTube (2016).

sobre 0 imaginário. Concebemos a zoolatria como uma marca dessa nova visualidade, na qual 0 sujeito contemporâneo vê a presença animal como mímese das nossas relações sociais, em que as qualidades e os defeitos do universo animal servem como metáfora das múltiplas condições da existência humana. A zoolatria deixa os espaços convencionais, como contos infantis, provérbios e animações, para assumir lugar de destaque nas narrativas midiáticas, principalmente através do consumo, por parte de jovens adultos, desses produtos que eram relacionados ao universo infantil.

Além disso, percebemos que o cotidiano se consagra como fórmula de produção de audiovisual na medida em que 0 cômico entra em cena, isto é, o cômico como espaço de produção de coesão social e de identificação entre os usuários.
Segundo Bergson (2007), o risível não existe fora da experiência humana; outras situações e condições podem existir para além da condição humana, mas o riso é um atributo humano, por excelência. Poderemos rir de um animal ou de um objeto quando ele assume 0 aspecto humano.

Nos vídeos do gato mal-humorado, vemos que o efeito do risível constrói-se a partir desse seu olhar, que se assemelha ao do aborrecimento humano. Isto é, o olhar do gato denota aspectos da expressão humana, como o mau humor, expresso pelo olhar fechado e pelos lábios curvados para baixo. Poderemos rir de um animal ou de um objeto quando ele assume 0 aspecto humano. 0 segundo aspecto do cômico, em Bergson (2007), é a condição social compartilhada do riso; o riso sempre é de um grupo, existe uma cumplicidade no efeito do riso, um aspecto de 
Figura 6: Canal de vídeos do gato mal-humorado no Youtube

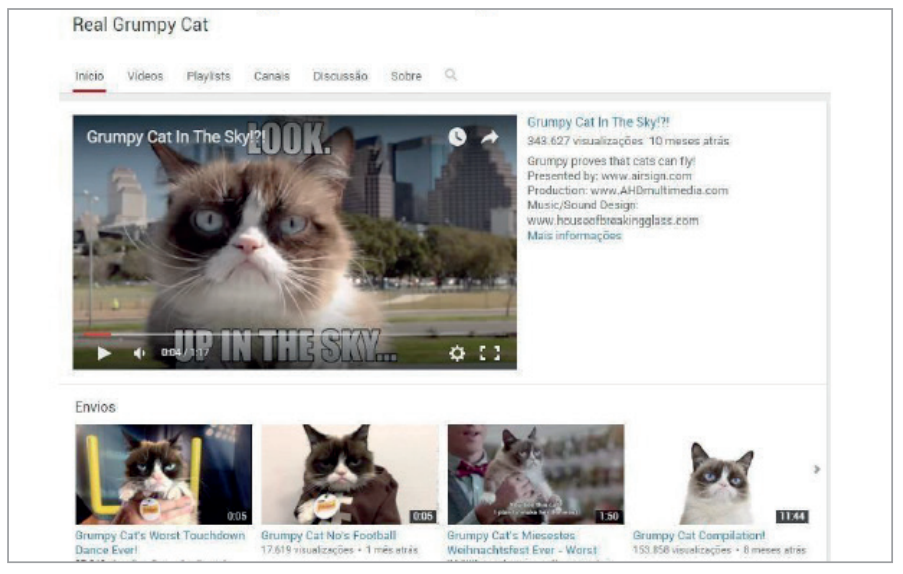

Fonte: YouTube (2016).

compartilhamento de um dado momento

ou situação de um determinado grupo, seja um evento real ou imaginário. 0 fenômeno do riso encontra-se em duas esferas, isto é, uma relação entre uma situação percebida intelectualmente e 0 aspecto de absurdo que essa situação evoca. É esse contraste entre 0 intelectualmente percebido e 0 absurdo produzido pela situação que consagra o risível em nossas sociedades.

Durand (2002) analisa que a escolha do animal no imaginário sobre 0 bestiário reflete os impulsos eleitos pelo seu grupo social. Acreditamos que a nova zoolatria privilegia os animais domésticos, em particular, o gato e 0 cachorro, por serem as melhores metáforas de sua condição com suas variações de humor, com as diversas personalidades. Assim, também há uma série de páginas de tom de humor em redes como Facebook, Twitter e Instagram que diariamente apresentam cenas cotidianas de animais. Como o exemplo, temos a página Catioro Reflexivo, no Facebook, com quase 4 milhões de seguidores. A principal estratégia da página é apresentar conteúdo com caráter de mímeses da ação humana, criando o efeito do risível.

Como destaca Durand (2002), a imaginação teriomórfica vem ocupar o espaço dos rituais. 0 animismo, para 0 autor (2002), é um elemento do retorno do espaço do símbolo, no campo social, uma atividade compensatória em relação à burocratização da vida social. Dessa forma, o animal, em vídeos no YouTube, representa um espaço de combinação do exercício psíquico humano através de elementos simbólicos.

Podemos também compreender 0 arquétipo animal, segundo Durand (2002), como um instrumento que vem resumir e clarificar os semantismos fragmentários de todos os símbolos 
Figura 7: Página do Facebook de Catiorro Reflexivo

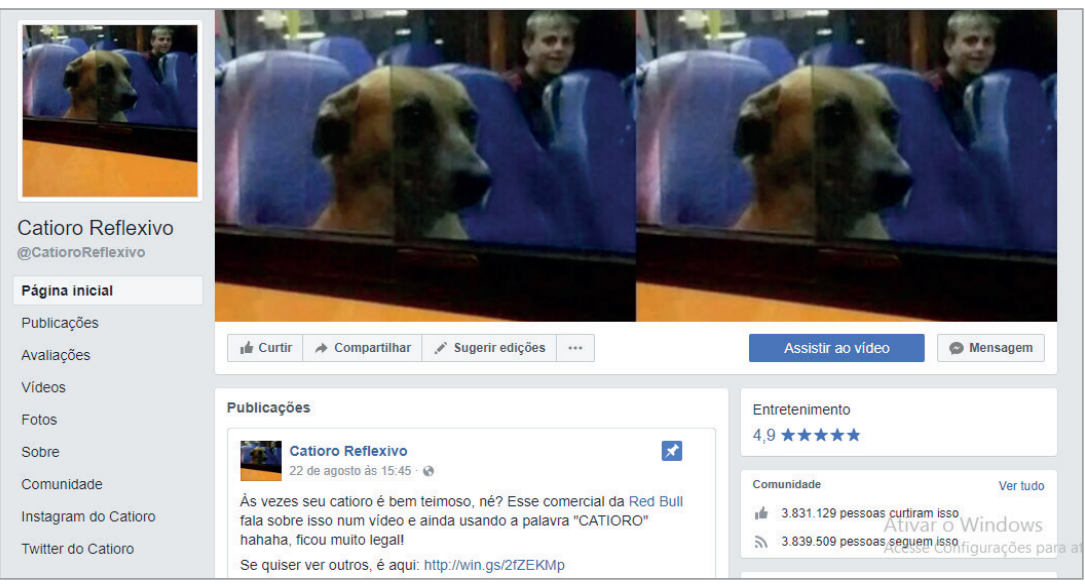

Fonte: Facebook (2017).

secundários. Portanto, assumimos 0 arquétipo animal como fonte do dinamismo psíquico reprimido durante a modernidade.

Maffesoli (2006) afirma que o arquétipo, o nó do inconsciente coletivo, que podemos perceber na publicidade, nos videoclipes e nos videogames, põe em cena as emoções de toda ordem, dinamiza toda a experiência social através de um clima de si pessoal, tributário de um si geral. De acordo com Maffesoli (2006), nesses momentos, os mitos encontram uma força atrativa ao se localizarem num ponto central do pensamento complexo. Assim, conforme 0 autor, devemos colocar 0 mito, 0 arquétipo e 0 imaginário no centro das temáticas do cotidiano.

É assim que 0 mito e 0 arquétipo, em suas expressões, são os criadores da iniciação pré e pós-moderna de socialização. Iniciação, socialização, estabilidade dos laços sociais, todos são baseados na interdependência ou, para colocá-lo através de um neologismo esclarecedor: na religação. É o que liga cada um à alteridade (religare), o que o deposita a confiança (realiant) com esta estranha alteridade (MAFFESOLI, 2006, p.92).

Na verdade, todas as imagens são imagens animais as mais frequentes e comuns. Pode-se dizer que não há nada mais familiar em nossa infância, representações de animais; mesmo 0 pequeno cidadão ocidental, 0 urso de pelúcia, gato de botas, mickey, veiculam estranhamente à mensagem teriomorfa. Metade dos títulos de livros para crianças são dedicados ao animal. Em trinta sonhos de infância relatados por Piaget mais ou menos nove se referem a sonhos com animais (DURAND, 2002, p.60).

Assim, definimos essa zoolatria identificada em vídeos no YouTube como sendo uma alternativa de compreender e valorizar os aspectos da dinâmica social considerados como a alteridade. A socialização dessa alteridade é negociada pelos 


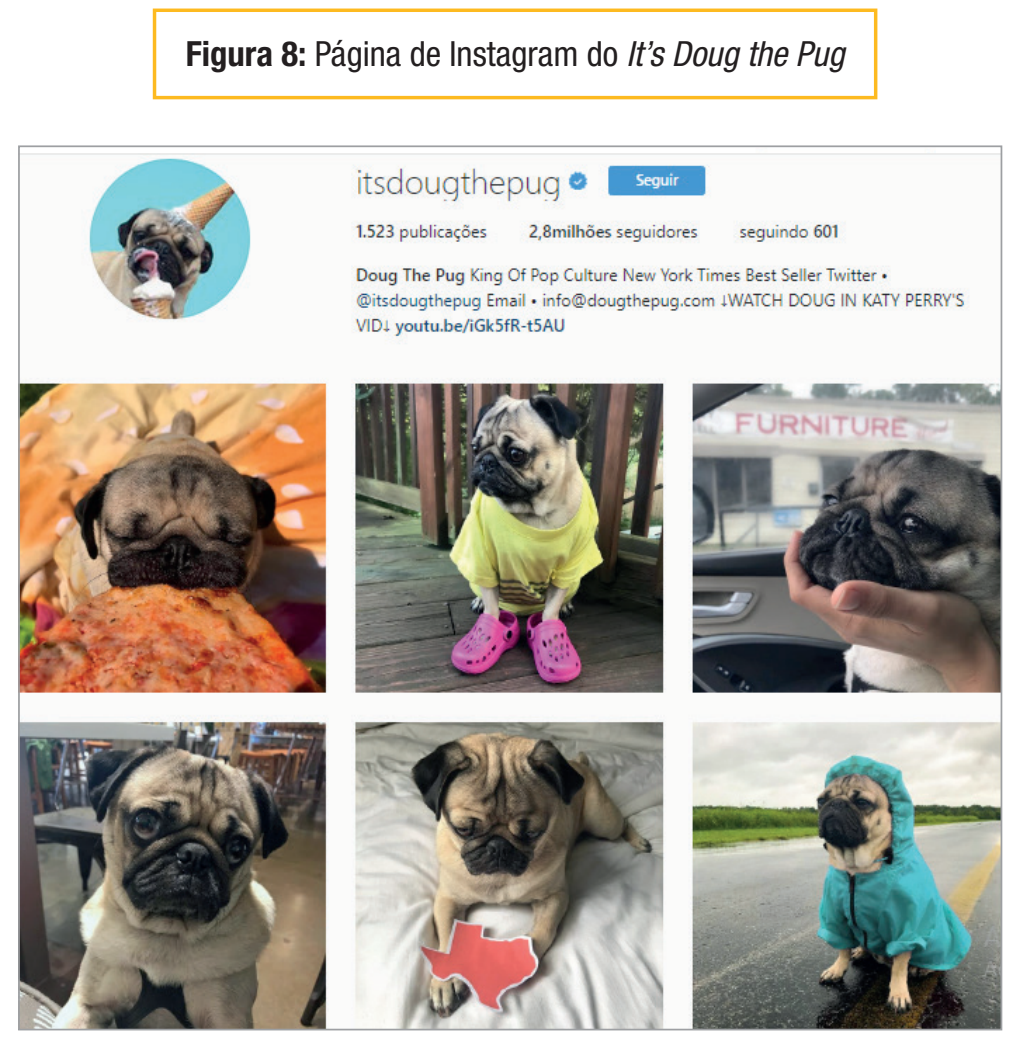

Fonte: Instagram (2017).

dispositivos visuais técnicos como 0 vídeo, no qual se produzem efeitos de interdependência entre setores dominantes.

Portanto, o imaginário é uma construção arquetípica que tem na natureza (meio) e na sua relação com o homem sua profunda base. A natureza e a forma como o homem se relaciona com ela fornecerão as imagens simbólicas plenas de sentidos que vão acompanhar nosso desenvolvimento. Quatro elementos da natureza serão as bases do imaginário bachelardiano que alimentarão a tradição epistemológica pela qual Durand (2002) irá acompanhar (mesmo que com algumas diferenças). Durand (1994, p. 3) considera o imaginário como o "museu de todas as imagens passadas, possíveis, produzidas e a produzir", nas diferentes modalidades da sua produção pelo homo sapiens sapiens.

Dessa forma, o vídeo liga os aspectos do isomorfismo entre espécie humana e de outros animais como uma ferramenta de integração de novos atores sociais dentro da dinâmica social. Com esse recurso, os aspectos míticos da zoolatria servem como um mediador simbólico dessas novas relações de socialização entre atores.

A zoolatria, na estética contemporânea, atende a condições de um devir humano que necessita de um espaço de expansão para um universo que metaforize as distintas condições de produção do 
sujeito, ou seja, um espaço de constituição de sentidos distintos da lógica cartesiana e mais próximas do sentido da vida.

\section{Considerações finais}

Compreendemos que a zoolatria identificada em vídeos, em redes sociais, pode ser compreendida também dentro de uma lógica de retorno do reprimido, apresentado por Jameson (2006), isto é, de conteúdos que foram sempre identificados como do universo da iniciação simbólica humana e que acabam por ganhar espaço dentro do universo adulto a partir de um ressurgimento de uma instância psíquica negada, o irracional. 0 irracional não identificado como negação da racionalidade, mas como uma racionalidade não humana e fonte de outros devires.

A zoolatria contemporânea nasce dentro de um paradigma que vem reconciliar os aspectos irracionais dentro de uma lógica saturada pelo racionalismo moderno e também numa perspectiva na qual as condições naturais de existência da vida no planeta tornam-se cada vez mais difíceis. Uma orientação holística de pensamento ambiental é parte constitutiva dessa zoolatria contemporânea, o holismo pré-moderno que vivia no bestiário medievo e antigo com seus dragões, grifos, etc. Por isso nossa ênfase anterior de apresentar uma relação entre elementos estéticos medievais e contemporâneos, pois observamos os dois fenômenos de estetização do mundo dentro de um paradigma não exclusivamente racional e partilhando de um holismo que, na Idade

Média, servia como método de reconciliação do passado greco-romano e, na contemporaneidade, serve como alternativa à aceleração temporal e degradação das condições de vida.

Verificamos que essa nova zoolatria vem embalada por uma rede de compartilhamento de afeto, em particular, sobre o registro dos animais domésticos. Há um crescimento de vídeos que apontam a ação animal como uma metáfora do humano. Além disso, há um investimento estético de parte de proprietários de animais domésticos em registrar os animais

\section{Referências}

BACHELARD, Gaston. A água e os sonhos. São Paulo: Martins Fontes, 1989.

BELTING, Hans. 0 fim da história da arte. São Paulo: Cosac Naify, 2006. Por uma antropologia da imagem.

Katz Editores, 2007.

BERGSON, Henri. La conscience et la vie.Paris: PUF, 2011.

. Le Possible et le Réel. Paris: PUF, 2011. Le Rire. Paris: PUF, 2007.

CASTELLS, Manuel. A sociedade em rede: a era da informação. Rio de Janeiro: Paz e Terra, 2005.

DELEUZE, Gilles. A imagem-tempo. São Paulo: Brasiliense, 2007.

. Bergsonismo. Rio de Janeiro: Editora 34, 1999. Diferença e repetição. São Paulo: Graal, 2004. 
; GUATTARI, Félix. 0 anti-Édipo: capitalismo

e esquizofrenia. Lisboa:Assírio \& Alvim, 2004.

DUMÉZIL, Georges. Godsancientnorthmen.

Los Angeles: UniversityofCalifornia Press,1973.

DURAND, Gilbert. L' imaginaire: essai sur les sciences et la philosophie de l'image. Paris:Hatier, 1994.

Campos do imaginário. Lisboa: Instituto

Piaget, 1996.

A imaginação simbólica. São Paulo: Cultrix, 1999.

Estruturas antropológicas do imaginário.

São Paulo: Martins Fontes, 2002.

ELIADE, Mircea. Imagens e símbolos. São Paulo:

Martins Fontes, 2002.

JAMESON, Fredric. Pós-modernismo, a lógica cultural do capitalismo tardio. São Paulo: Ática, 2006.

LÉVI-STRAUSS, Claude. 0 Pensamento Selvagem.

São Paulo: Papirus, 2008.

MAFFESOLI, Michel. 0 tempo das tribos: 0 declínio do individualismo nas sociedades demassa. Rio de Janeiro: Forense Universitária, 2006.

MATURANA, Humberto e VARELA, Francisco. De máquinas e seres vivos. Autopoiese, a Organização do Vivo. Porto Alegre: Artes Médicas, 1997.

MORIN, Edgar. Introdução ao pensamento complexo. Porto Alegre: Sulina, 2001.

YOUTUBE. YouTube. Disponível em: < https://www. youtube.com/>. Acesso em: 2016. 


\section{Animals - For a new zoolatry}

\section{Abstract}

The article investigates the emergence of a new zoolatry, linked to domestic animals in the online network, especially on YouTube. Through the Animals video (Martin Garrix), the article proposal analyzes how the human condition presents itself as metaphors linked to animals. Our methodology contemplates the analysis of the constitution of the imaginary and the mythical universes, through the mitocritic of Gilbert Durand. Our findings evidence that this movement toward video recording of animal life is a compensatory symbolic action as well as a reintegration of man into the new setting in which nature is revitalized by ecological discourses.

\section{Keywords}

Zoolatry. Video. Animals. Environment.

\section{Animales - Para una nueva zoolatría}

\section{Resumen}

El artículo investiga la aparición de una nueva zoolatría, vinculada a animales domésticos, especialmente presentada en videos en Youtube. A través del video de Animals (Martin Garrix), la propuesta de investigación analiza cómo la condición humana se presenta a sí misma como metáforas vinculadas al universo animal. Nuestra metodología contempla el análisis de la constitución de los universos imaginario y mítico, a través de la mitocrítica de Gilbert Durand. Nuestros hallazgos muestran que este movimiento hacia la grabación de video de la vida animal es una acción compensatoria simbólica y también una reintegración del hombre en el nuevo escenario en el que la naturaleza se revitaliza mediante discursos ecológicos.

\section{Palabras-clave}

Zoolatría. Video. Animales. Medio ambiente. 


\section{Expediente}

A revista E-Compós é a publicação científica em formato eletrônico da Associação Nacional dos Programas de Pós-Graduação em Comunicação (Compós). Lançada em 2004, tem como principal finalidade difundir a produção acadêmica de pesquisadores da área de Comunicação, inseridos em instituições do Brasil e do exterior.

\section{E-COMPÓS I www.e-compos.org.br I E-ISSN 1808-2599}

Revista da Associação Nacional dos Programas de Pós-Graduação em Comunicação. Brasília, v.21, n.3, set/dez. 2018. A identificação das edições, a partir de 2008, passa a ser volume anual com três números. Indexada por Latindex I www.latindex.unam.mx

\section{CONSELHO EDITORIAL}

Ada Cristina Machado Silveira, Universidade Federal de Santa Maria, Brasi Alda Cristina Silva da Costa, Universidade Federal do Pará, Brasil Alfredo Luiz Paes de Oliveira Suppia, Universidade Estadual de Campinas, Brasil Ana Carolina Rocha Pessôa Temer, Universidade Federal de Goiás, Brasil Ana Regina Barros Rego Leal, Universidade Federal do Piauí, Brasil André Luiz Martins Lemos, Universidade Federal da Bahia, Brasil Angela Cristina Salgueiro Marques, Universidade Federal de Minas Gerais, Brasil Ângela Freire Prysthon, Universidade Federal de Pernambuco, Brasil Anna Cristina Pertierra, Western Sidney University, Austrália Antonio Carlos Hohlfeldt, Pontifícia Universidade Católica do Rio Grande do Sul, Brasi Arthur Ituassu, Pontifícia Universidade Católica do Rio de Janeiro, Brasil Bruno Campanella, Universidade Federal Fluminense, Brasil Bushra Hameedur Rahman, University of the Punjab, Paquistão, Paquistão Cárlida Emerim, Universidade Federal de Santa Catarina, Brasil Carlos Del Valle Rojas, Universidad de La Frontera, Chile Carlos Eduardo Franciscato, Universidade Federal de Sergipe, Brasil Cláudio Novaes Pinto Coelho, Faculdade Cásper Líbero, Brasil Danilo Rothberg, Universidade Estadual Paulista, Brasil Denise Tavares, Universidade Federal Fluminense, Brasil Diógenes Lycarião, Universidade Federal do Ceará, Brasil Dóris Martínez Vizcarrondo, Universidad de Puerto Rico Mayagüez, Porto Rico Eduardo Vicente, Universidade de São Paulo, Brasil

Eliza Bachega Casadei, Escola Superior de Propaganda e Marketing - SP, Brasil Elvira Gomes dos Reis Freitas, Universidade de Cabo Verde, Cabo Verde Eneus Trindade, Universidade de São Paulo, Brasil Erick Felinto de Oliveira, Universidade do Estado do Rio de Janeiro, Brasil Erick Torrico, Universidad Andina Simón Bolívar, Bolívia, Bolívia Erly Vieira Júnior, Universidade Federal do Espírito Santo, Brasil Fabio La Rocca, Université Paul-Valéry Montpellier 3, França Fernando Firmino da Silva, Universidade Federal da Paraíba, Brasil Francisco de Assis, FIAM-FAAM Centro Universitário, Brasil Francisco Elinaldo Teixeira, Universidade Estadual de Campinas, Brasil Francisco Gilson Rebouças Pôrto Junior, Universidade Federal do Tocantins, Brasil Francisco Sierra Caballero, CIESPAL, Equador Frederico de Mello Brandão Tavares, Universidade Federal de Ouro Preto, Brasil Gabriela Reinaldo, Universidade Federal do Ceará, Brasil Germán Rey Beltrán, Universidad Nacional de Colombia, Colômbia Gilson Vieira Monteiro, Universidade Federal do Sul da Bahia, Brasil Gustavo Daudt Fischer, Universidade do Vale do Rio dos Sinos, Brasil Gustavo Hernández Díaz, Universidad Central de Venezuela, Venezuela Heidi Figueroa Sarriera, Universidad de Puerto Rico, Porto Rico Ignacio Aguaded, Universidad Huelva, Espanha Inesita Soares de Araújo, FIOCRUZ, Brasil Itania Maria Mota Gomes, Universidade Federal da Bahia, Brasil Jiani Adriana Bonin, Universidade do Vale do Rio dos Sinos, Brasi João Carlos Ferreira Correia, Universidade da Beira Interior, Portugal Jonathan Cohen, University of Haifa, Israel José Afonso da Silva Junior, Universidade Federal de Pernambuco, Brasil José Luiz Aidar Prado, Pontifícia Universidade Católica de São Paulo, Brasil Josette Maria Monzani, Universidade Federal de São Carlos, Brasil Juçara Gorski Brittes, Universidade Federal de Ouro Preto, Brasil Julián Durazo Hermann, Université du Québec à Montreal, Canadá Juliana Freire Gutmann, Universidade Federal da Bahia, Brasil
Karla Yolanda Covarrubias, Universidad de Colima, México Laura Loguercio Cánepa, Universidade Anhembi Morumbi, Brasil Leonel Azevedo de Aguiar, Pontifícia Universidade Católica do Rio de Janeiro, Brasil Leticia Cantarela Matheus, Universidade do Estado do Rio de Janeiro, Brasil Ling Chen, Hong Kong Baptist University, China Luciana Coutinho Souza, Universidade de Sorocaba, Brasil Marcel Vieira Barreto Silva, Universidade Federal da Paraíba, Brasil Marcia Tondato, Escola Superior de Propaganda e Marketing, Brasil Márcio Souza Gonçalves, Universidade do Estado do Rio de Janeiro, Brasil Maria Ataide Malcher, Universidade Federal do Pará, Brasil Maria das Graças Pinto Coelho, Universidade Federal do Rio Grande do Norte, Brasi Maria Elena Hernández Ramirez, Universidad de Guadalajara, México Maria Elisabete Antonioli, Escola Superior de Propaganda e Marketing - SP, Brasil Maria Teresa Quiroz, Universidad de Lima, Peru Marialva Carlos Barbosa, Universidade Federal do Rio de Janeiro, Brasil Marina Poggi, Universidad Nacional de Quilmes, Argentina Marli Santos, Faculdade Cásper Líbero, Brasil Mateus Yuri Passos, Universidade Metodista de São Paulo, Brasil Mauricio Mario Monteiro, Universidade Anhembi Morumbi, Brasil, Brasil Mayka Castellano, Universidade Federal Fluminense, Brasil Mirta Varela, Universidad de Buenos Aires, Argentina

Mozahir Salomão Bruck, Pontifícia Universidade Católica de Minas Gerais, Brasil Neyla Graciela Pardo Abril, Universidad Nacional de Colombia, Colômbia Nísia Martins Rosario, Universidade Federal do Rio Grande do Sul, Brasil Olga Guedes Bailey, Nottingham Trent University, Reino Unido Paolo Demuru, Universidade Paulista, Brasil

Paolo Peverini, LUISS, Itália

Paško Bilić, Institute for Development and International Relations, Croácia Paula Melani Rocha, Universidade Estadual de Ponta Grossa, Brasil Potiguara Mendes Silveira Jr, Universidade Federal de Juiz de Fora, Brasil Rafael Cardoso Sampaio, Universidade Federal do Paraná, Brasil Rafael Tassi Teixeira, Universidade Tuiuti do Paraná, Brasil Regiane Lucas de Oliveira Garcêz, Universidade Federal de Minas Gerais, Brasil Regiane Regina Ribeiro, Universidade Federal do Paraná, Brasil Renata Pitombo Cidreira, Universidade Federal do Recôncavo da Bahia, Brasil Renato Essenfelder, Escola Superior de Propaganda e Marketing, Brasil Roberto Elísio dos Santos, Universidade Municipal de São Caetano do Sul, Brasil Robson Borges Dias, Universidade Católica de Brasília (UCB), Brasil Rodolfo Rorato Londero, Universidade Estadual de Londrina, Brasil Rosario Sanchéz Vilela, Universidad Católica del Uruguay, Uruguai Roseli Figaro, Universidade de São Paulo, Brasil Saima Saeed, Jamia Millia Islamia, India Sara Brandellero, Leyden University, Holanda Simone Maria Andrade Pereira de Sá, Universidade Federal Fluminense, Brasil Sônia Caldas Pessoa, Universidade Federal de Minas Gerais, Brasil Sun Sun Lim, Singapore University of Technology and Design, Singapura Tatiana Oliveira Siciliano, Pontifícia Universidade Católica do Rio de Janeiro, Brasil Thaïs de Mendonça Jorge, Universidade de Brasília, Brasil Valquiria Michela John, Universidade Federal do Paraná, Brasil Vicky Mayer, Tulane University, Estados Unidos da América do Norte Yamile Haber Guerra, Universidad de Oriente, Cuba 


\section{CONSELHO CIENTÍFICO}

Cristiane Freitas Gutfreind, Pontifícia Universidade Católica do Rio Grande do Sul, Brasil I Eduardo Antonio de Jesus, Universidade Federal de Minas Gerais, Brasil I Eduardo Morettin, Universidade de São Paulo, Brasil I Irene de Araújo Machado, Universidade de São Paulo, Brasil

\section{COMISSÃO EDITORIAL}

Igor Pinto Sacramento, Universidade Federal do Rio de Janeiro, Brasil I Kelly Cristina de Souza Prudencio, Universidade Federal do Paraná, Brasil | Miriam de Souza Rossini, Universidade Federal do Rio Grande do Sul, Brasil

\section{EDITORES ASSOCIADOS}

Rafael Grohmann, Faculdade Cásper Líbero, Brasil I Thaiane Moreira de Oliveira, Universidade Federal Fluminense, Brasil

\section{CONSULTORES AD HOC}

Ada Machado, Universidade Federal de Santa Maria, Brasil | Ana Carolina Escosteguy, Universidade Federal de Santa Maria, Brasil | Andrea França, Pontifícia Universidade Católica do Rio de Janeiro, Brasil | Ariane Holzbach, Universidade Federal Fluminense, Brasil | Benjamim Picado, Birkbeck College, Inglattera | Bruno Souza Leal, Universidade Federal de Minas Gerais, Brasil I Eduardo Morettin, Universidade de São Paulo, Brasil I Felipe Trotta, Universidade Federal Fluminense, Brasil | Francisco Rüdiger, Pontifícia Universidade Católica do Rio Grande do Sul, Brasil | Gislene da Silva, Universidade Federal de Santa Catarina, Brasil | Inês Vitorino, Universidade Federal do Ceará, Brasil I Isaltina Gomes, Universidade Federal de Pernambuco, Brasil I Jairo Ferreira, Universidade do Vale do Rio dos Sinos, Brasil I Karina Janz, Universidade Estadual de Ponta Grossa, Brasil I Kati Caetano, Universidade Tuiuti do Paraná, Brasil I Lilian França, Universidade Federal do Sergipe, Brasil I Liziane Guazina, Universidade de Brasília, Brasil I Márcio de Vasconcellos Serelle, Pontifícia Universidade Católica de Minas Gerais, Brasil I Marta Maia, Universidade Federal de Ouro Preto, Brasil I Maurício de Bragança, Universidade Federal Fluminense, Brasil I Nina Velasco e Cruz, Universidade Federal de Pernambuco, Brasil | Norval Baitello Jr., Pontifícia Universidade Católica de São Paulo, Brasil | Pedro Guimarães, Universidade do Estado do Rio de Janeiro, Brasil | Priscilla Perazzo, Universidade Municipal de São Caetano do Sul, Brasil I Sofia Zanforlin, International Association of Media and Communication Research, Estados Unidos I Talitha Ferraz, Escola Superior de Propaganda e Marketing, Brasil I Tattiana Teixeira, Universidade Federal de Santa Catarina, Brasil I Victa de Carvalho Pereira da Silva, Universidade Federal do Rio de Janeiro, Brasil

\section{EQUIPE DE EDITORAÇÃO}

ASSISTENTE EDITORIAL Marcio Telles | REVISÃO DE TEXTOS Fátima Áli | EDITORAÇÃO ELETRÔNICA Roka Estúdio

COMPÓS I www.compos.org.br

Associação Nacional dos Programas de Pós-Graduação em Comunicação

Presidente

Marco Roxo

Programa de Pós-Graduação em Comunicação - UFF

marcos-roxo@uol.com.br

Vice-Presidente

Isaltina Gomes

Programa de Pós-Graduação em Comunicação - UFPE

isaltina@gmail.com

Secretária-Geral

Gisela Castro

Programa de Pós-Graduação em Comunicação

e Práticas de Consumo - ESPM

castro.gisela@gmail.com

CONTATO I revistaecompos@gmail.com 